\title{
Design of Long Persistent White Phosphorescence in a Composite Phosphor Via Energy Transfer Mechanism
}

\author{
Hom Nath Luitel ${ }^{1,2,{ }^{*}, \text { Rumi Chand }}{ }^{1}$, Toshio Torikai ${ }^{1}$, Mitsunori Yada ${ }^{1}$, Takanori Watari ${ }^{1}$ \\ ${ }^{1}$ Department of Advanced Technology Fusion, Saga University, Honjo-1, Saga 840-8502, Japan \\ ${ }^{2}$ GBRY Co. Ltd., 1-62-6-201 Higashiyama, Hirakata City, Osaka, 570-003, Japan
}

Email address:

mehomnath@yahoo.com (H. N. Luitel), rumichand@gmail.com (R. Chand), torikait@cc.saga-u.ac.jp (T. Torikai), yada@cc.saga-u.ac.jp (M. Yada), watarit@cc.saga-u.ac.jp (T. Watari)

\section{To cite this article:}

Hom Nath Luitel, Rumi Chand, Toshio Torikai, Mitsunori Yada, Takanori Watari. Design of Long Persistent White Phosphorescence in a Composite Phosphor Via Energy Transfer Mechanism. International Journal of Materials Science and Applications.

Vol. 4, No. 2, 2015, pp. 107-114. doi: 10.11648/j.ijmsa.20150402.16

\begin{abstract}
A high quality composite phosphor powder of warm to cool white emission and long afterglow phosphorescence was reported by the process of energy transfer in a composite phosphor. The composite phosphor particles include at least two types of phosphor particles viz. a blue white persistent component and yellow fluorescent component. The blue white extremely long persistent component transfers its afterglow to the yellow fluorescent component in the composite phosphor followed by the color mixing process to generate the white afterglow. The composite phosphor is designed in such a way that the excitation spectrum of the fluorescent component was overlapped as much with the afterglow emission of the persistent component. The composite phosphor emission spectrum can be well tuned from warm to cool white depending on the proportions of the composite phosphors and energy transfer extent. Phosphor includes powders, ceramics and resin composites.
\end{abstract}

Keywords: Luminescence, White Afterglow, Composite, Energy Transfer

\section{Introduction}

Persistent phosphorescence was discovered in the $11^{\text {th }}$ century in China and Japan and in the $16^{\text {th }}$ century in Europe [1]. The phosphorescent dynamics are complex and many aspects still remain unclear. Generally, the phosphorescence phenomenon involves two kinds of active centers: emitters and traps. Phosphorescence is physically governed by the traps concentration and their depths in the host matrix generated by deformation of the host or adding some impurities [2, 3]. Phosphorescence intensity is being dependent on the concentration of traps while the depth of traps governs the persistent time. When a phosphor possesses centers with certain trapping depth which can be effectively activated at room temperature, it shows persistent phosphorescence. Much deeper trapping centers can only be activated by heating or photo-stimulation, thus unsuitable for the room temperature phosphorescence.

Persistent phosphorescent materials, such as $\mathrm{ZnCdS}: \mathrm{Cu}$, $\mathrm{ZnS}: \mathrm{Cu}, \mathrm{Co}$ and $\mathrm{CaS} / \mathrm{SrS}: \mathrm{Bi}$, have been used for many years $[1,4]$. Such phosphorescent pigments and luminous pigments are currently used for various products utilizing their long afterglow characteristics, for example, switches, lights for carrying, articles for use in darkroom, handrails, luminous indications such as wall indications, guidance signs, escape tools, other phosphorescent indications such as phosphorescent safety marks, ornamental articles such as ash trays, earrings and table cloths, printed matter, toys, stationery and the like. For example, as uses of the phosphorescent pigments, Japanese Patents disclose phosphorescent wall panels for escape corridor [5], phosphorescent fibers [6], light emitting ropes [7], and phosphorescent sheets for indications [8].

Strong green luminescence from $\mathrm{SrAl}_{2} \mathrm{O}_{4}: \mathrm{Eu}^{2+}, \mathrm{Dy}^{3+}$ was reported by Yamamoto et. al. in 1997 [9]. Efficient luminescence in the blue to green $(450-520 \mathrm{~nm})$ was also reported from $\mathrm{Eu}^{2+}$-doped $\mathrm{CaAl}_{2} \mathrm{O}_{4}, \mathrm{SrAl}_{2} \mathrm{O}_{4}$ and $\mathrm{BaAl}_{2} \mathrm{O}_{4}$ $[10,11]$. Recently, a much brighter and longer persistent blue-green phosphor; $\mathrm{Sr}_{4} \mathrm{Al}_{14} \mathrm{O}_{25}: \mathrm{Eu}^{2+}, \mathrm{Dy}^{3+}$ has been reported and in commercial use [12-16]. However, there is still lack of efficient and long afterglow in the yellow, red and white spectrum making limited application of the persistent phosphors.

Energy transfer and color mixing to generate a complimentary color is well known phenomenon in LED 
technology. For example, white light is generated from the bi-color mixing of blue light from InGaN blue LED and yellow light from the blue LED excited YAG: $\mathrm{Ce}^{3+}$ phosphor [17-21]. However, this phenomenon has not yet been accepted for the long afterglow phosphors due to heterogeneous afterglow.

Herein, we illustrate very long and bright white afterglow generated from the easily available, extremely long blue white afterglow phosphor, $\mathrm{CaAl}_{2} \mathrm{O}_{4}: \mathrm{Eu}^{2+}, \mathrm{Nd}^{3+}, \mathrm{Dy}^{3+} / \mathrm{Sr}_{4} \mathrm{Al}_{14} \mathrm{O}_{25}: \mathrm{Eu}^{2+}, \mathrm{Dy}^{3+}, \mathrm{Ag}^{+}, \quad$ and highly efficient yellow fluorescent phosphor, $\mathrm{Sr}_{2.89}$ ${ }_{\mathrm{x}} \mathrm{Zn}_{0.1} \mathrm{SiO}_{5}: \mathrm{xEu}^{2+}$. The origin of the white phosphorescence is accompanied by the energy transfer process from blue white (BW) long afterglow phosphor to the yellow fluorescent phosphor and color mixing to generate the white afterglow.

\section{Experimental}

Extremely long persistent blue-green (BG) phosphor, $\mathrm{Sr}_{4} \mathrm{Al}_{14} \mathrm{O}_{25}: \mathrm{Eu}^{2+}, \mathrm{Dy}^{3+}, \mathrm{Ag}^{+}$, was prepared according to our previous report [12]. The blue white (BW) persistent phosphor was then prepared by mixing small amount of blue phosphor, $\mathrm{CaAl}_{2} \mathrm{O}_{4}: \mathrm{Eu}^{2+}, \mathrm{Nd}^{3+}, \mathrm{Dy}^{3+}$, to the $\mathrm{BG}$ phosphor. The $\mathrm{CaAl}_{2} \mathrm{O}_{4}: \mathrm{Eu}^{2+}, \mathrm{Nd}^{3+}, \mathrm{Dy}^{3+}$ blue phosphor was prepared according the literature [9, 22]. The yellow fluorescent phosphors $\mathrm{Sr}_{3-\mathrm{x}-\mathrm{y}} \mathrm{Zn}_{\mathrm{y}} \mathrm{SiO}_{5}: \mathrm{xEu}^{2+}$ were prepared by the reaction between strontium carbonate $\left(\mathrm{SrCO}_{3}\right.$; Aldrich, $\left.99.9 \%\right)$, zinc oxide ( $\mathrm{ZnO}$; Aldrich, 99.5\%), fumed silica $\left(\mathrm{SiO}_{2}\right.$, Aldrich, 7 $\mathrm{nm}, \mathrm{AR})$ and europium oxide $\left(\mathrm{Eu}_{2} \mathrm{O}_{3}\right.$; Aldrich, $\left.99.99 \%\right)$ in a reducing atmosphere of $\mathrm{H}_{2} / \mathrm{N}_{2}=1 / 9\left(20 \mathrm{ml} \mathrm{H}_{2} / 180 \mathrm{ml} \mathrm{N}\right.$ ) at various temperatures $\left(1100-1450{ }^{\circ} \mathrm{C}\right)$ for 4 to $6 \mathrm{~h}$. Powders were weighed according to the chemical compositions of (3$\mathrm{x}$-y) $\mathrm{SrCO}_{3}+1 \mathrm{SiO}_{2}+\mathrm{x}$ at $\% \mathrm{Eu}+\mathrm{y}$ at $\% \mathrm{Zn}$. The appropriate amounts of the starting materials according to the derived compositions were mixed thoroughly in a mortar and pestle with the help of ethanol. The mixture was allowed to dry to form powder and prepared in the form of pellets $(\varnothing 13 \mathrm{~mm} \mathrm{x}$ $3 \mathrm{~mm}$ dimension) applying $650 \mathrm{~kg} . \mathrm{cm}^{-2}$ biaxial pressure for 3 minutes. These pellets were heated in a reducing atmosphere. The products obtained after reduction were gritty solid that was pulverized to get fine powder.

The composite persistent phosphors powder were prepared by dry ball milling the different wt.\% of the persistent phosphor and fluorescent phosphor. The resin or epoxy compacts were prepared by mixing the transparent resin or epoxy with the composite persistent phosphor in various wt.\%. The ceramics compacts were prepared by thoroughly mixing the glass frit (softening temperature below $600{ }^{\circ} \mathrm{C}$ ) with composite persistent phosphor in various wt.\% and firing the mixture from 600 to $800^{\circ} \mathrm{C}$ in air ambient.

Phase identification was carried out using a Shimadzu6300 X-ray diffractometer with $\mathrm{Cu}-\mathrm{K} \alpha$ radiation. Photoluminescence (PL) emission and phosphorescence spectra were recorded using USB 4000-UV-VIS-NIR fiber optic spectrometer (Ocean optics). PL excitation spectra and absolute quantum yields were measured using Hamamatsu Quantaurus QY absolute quantum yield instrument. The decay curves were recorded using a brightness meter (Konica Minolta LS-100) equipped with RS232C Comm. Before afterglow and decay curves measurements, each sample was exposed to $15 \mathrm{~W}$ D65 lamps for 20 minutes. All measurements were carried out at room temperatures unless specified.

\section{Result and Discussion}

Figure 1 shows the PL excitation, emission and phosphorescence spectra of the extremely long blue white afterglow phosphor, $\mathrm{CaAl}_{2} \mathrm{O}_{4}: \mathrm{Eu}^{2+}, \mathrm{Nd}^{3+}, \mathrm{Dy}^{3+} / \mathrm{Sr}_{4} \mathrm{Al}_{14} \mathrm{O}_{25}: \mathrm{Eu}^{2+}, \mathrm{Dy}^{3+}, \mathrm{Ag}^{+}$, prepared according to previous reports [9-10, 12-14, 22]. From Figure 1 it is clear that the phosphor can be excited by UV $(\sim 250 \mathrm{~nm})$ to blue light $(440 \mathrm{~nm})$. The phosphor exhibited bluish white emission with broad emission band from $430 \mathrm{~nm}$ to $500 \mathrm{~nm}$ and similar phosphorescence spectrum. The initial phosphorescence intensity of the phosphor decreased rapidly with the elapse of time and attained persistent phosphorescence after couple of minutes. The initial luminescence intensity of the phosphor was $\sim 20,000 \mathrm{mcd} . \mathrm{m}^{-2}$ that decreased to about 100 mcd. $\mathrm{m}^{-2}$ within 10 minutes and afterward marginally decreased showing bright bluish phosphorescence for more than 10 hours above the value of 5 mcd. $\mathrm{m}^{-2}$.

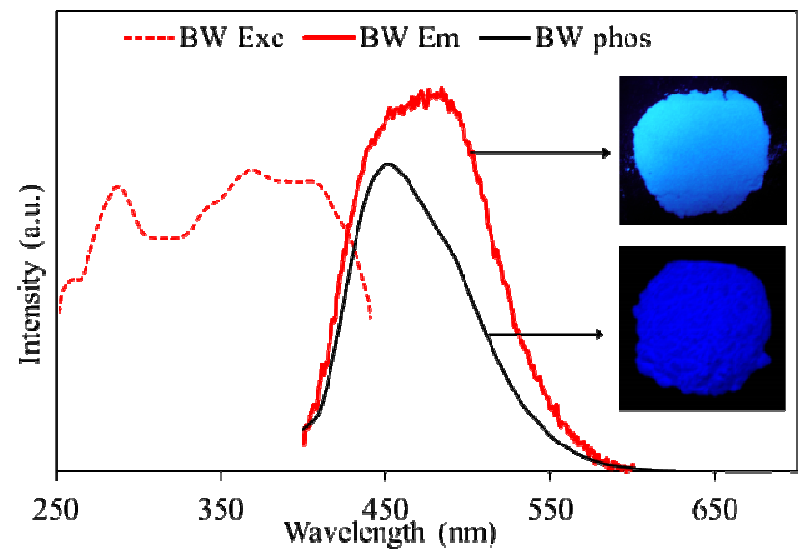

Figure 1. PL excitation, emission and phosphorescence spectra of the long afterglow blue white $\left(\mathrm{CaAl}_{2} \mathrm{O}_{4}: \mathrm{Eu}^{2+}{ }^{2} \mathrm{Nd}^{3+}, \mathrm{Dy}^{3+} / \mathrm{Sr}_{4} \mathrm{Al}_{14} \mathrm{O}_{25}: \mathrm{Eu}^{2+}, \mathrm{Dy}^{3+}, \mathrm{Ag}^{+}\right)$ phosphor (inset is the optical photographs during $B L$ irradiation and afterglow at $10 \mathrm{sec}$.).

Figure 2 shows the PL excitation and fluorescence spectra of the $\mathrm{Sr}_{2.99} \mathrm{SiO}_{5}: 1$ at $\% \mathrm{Eu}^{2+}$ and $\mathrm{Sr}_{2.89} \mathrm{Zn}_{0.1} \mathrm{SiO}_{5}: 1$ at $\% \mathrm{Eu}^{2+}$ phosphors prepared at $1400{ }^{\circ} \mathrm{C}$ for $4 \mathrm{~h}$ in $10 \% \mathrm{H}_{2}-90 \% \mathrm{~N}_{2}$ atmosphere. The $\mathrm{Sr}_{2.99} \mathrm{SiO}_{5}: 1$ at $\% \mathrm{Eu}^{2+}$ phosphor exhibited bright yellow fluorescence from $530 \mathrm{~nm}$ to $650 \mathrm{~nm}$ under black light exposure. The excitation spectrum of the phosphor was also very wide ranging from below $250 \mathrm{~nm}$ to above $500 \mathrm{~nm}$. A series of $\mathrm{Sr}_{3-\mathrm{x}-\mathrm{y}} \mathrm{Zn}_{\mathrm{y}} \mathrm{SiO}_{5}: \mathrm{xEu}^{2+}(\mathrm{x}=0.01$ and $\mathrm{y}=0$ to 0.5$)$ phosphors with different moles of $\mathrm{Zn}$ substitution at the $\mathrm{Sr}$ sites were prepared and corresponding emission spectra are presented in Figure 3. With the increase of $\mathrm{Zn}$ concentration the yellow emission intensity increased 
till 0.1 moles, above that it decreased gradually. At the same time the shoulder at green region was much pronounced by the addition of zinc. Interestingly, the excitation spectrum of the $\mathrm{Zn}$ substituted samples showed significant red shift. As seen in Figure 2, the 0.1 moles $\mathrm{Zn}$ substituted $\mathrm{Sr}_{2.89} \mathrm{Zn}_{0.1} \mathrm{SiO}_{5}: 1$ at $\% \mathrm{Eu}^{2+}$ phosphor exhibited pronounced red shift which was extended up to about $550 \mathrm{~nm}$. From the detail XRD analyses of the various moles of $\mathrm{Zn}$ substituted $\mathrm{Sr}_{3-\mathrm{x}-\mathrm{y}} \mathrm{Zn}_{\mathrm{y}} \mathrm{SiO}_{5}: \mathrm{xEu}^{2+}(\mathrm{x}=0.01$ and $\mathrm{y}=0$ to 0.5$)$ phosphor samples as shown in Figure 4, it was found that some $\mathrm{Sr}_{2} \mathrm{SiO}_{4}$ phase co-existed with the increase of the $\mathrm{Zn}$ content. The $\mathrm{Sr}_{2} \mathrm{SiO}_{4}: \mathrm{Eu}^{2+}$ was found to exhibit greenish yellow fluorescence under black light irradiation [23]. Further, no any $\mathrm{ZnO}$ phase was observed up to 0.15 moles of $\mathrm{Zn}$ substitution into the $\mathrm{Sr}_{2.89} \mathrm{Zn}_{\mathrm{x}} \mathrm{SiO}_{5}: 1$ at $\% \mathrm{Eu}^{2+}$ phosphor indicating the formation of solid solution of $\mathrm{ZnO}$ in to the
$\mathrm{Sr}_{3} \mathrm{SiO}_{5} / \mathrm{Sr}_{2} \mathrm{SiO}_{4}$ matrix. It is well established phenomena that $\mathrm{Ge}, \mathrm{Si}$ or other low band gap impurities substitution in to the various matrixes significantly decreased the band gap of the host $[17,24-26]$. This effect is explained by the fact that the wave functions of the electrons bound to the impurity atoms start to overlap as the density of the impurities increases. For instance at a doping concentration of $0.01 \mathrm{~mol} \%$ (density of $\sim 10^{18} \mathrm{~cm}^{-3}$ ), the average distance between two impurities is only $10 \mathrm{~nm}$. This overlap forces the energies to form an energy band rather than a discrete level and significantly reduces the band gap. Most probably, small amount of $\mathrm{ZnO}$ doping (10 mol\% $\mathrm{Zn}$, corresponding to about $2.3 \times 10^{21} \mathrm{~cm}^{-3}$ ) in to the $\mathrm{Sr}_{3} \mathrm{SiO}_{5}$ matrix creates bands in between the valance and conduction bands of the $\mathrm{Sr}_{3} \mathrm{SiO}_{5}$ host matrix and reduces the band gap thus extending the excitation spectrum to longer wavelength.

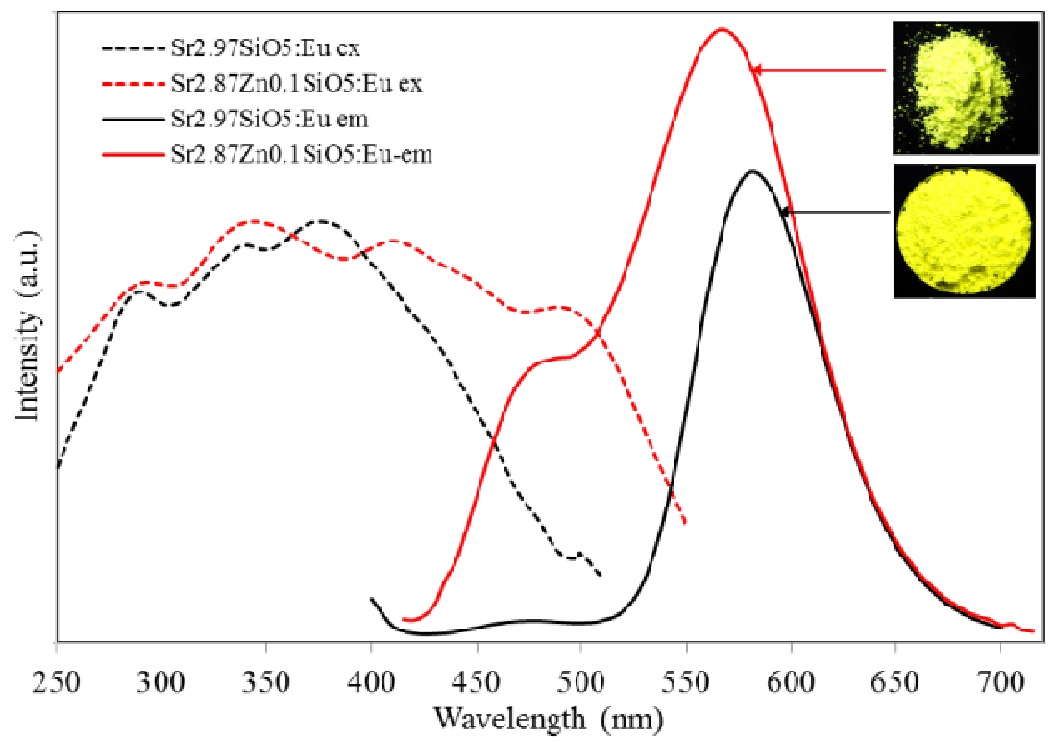

Figure 2.PL excitation (em@565nm) and emission (ex@450nm) spectra of $\mathrm{Sr}_{2.99} \mathrm{SiO}_{5}: 1$ at $\% \mathrm{Eu}^{2+}$ and $\mathrm{Sr}_{2.89} \mathrm{Zn}_{0.1} \mathrm{SiO}_{5}: 1$ at\% Eu $\mathrm{Eu}^{2+}$ yellow fluorescence phosphor (inset is the corresponding optical photographs during BL irradiation).

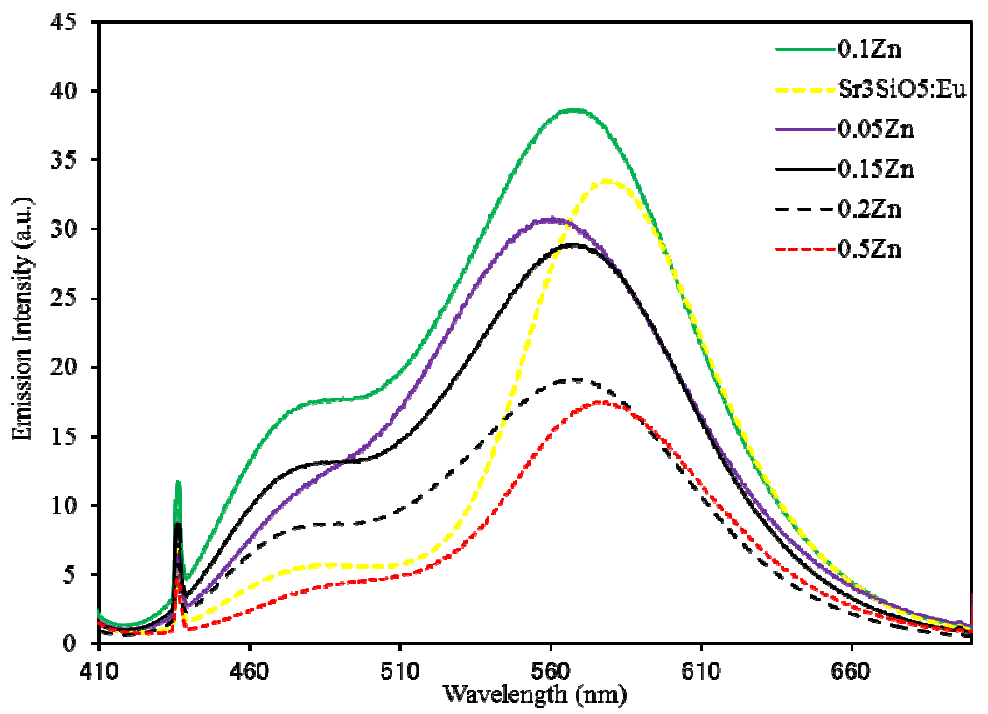

Figure 3. PL emission (ex@365nm black light) spectra of $\mathrm{Sr}_{2.99-y} \mathrm{Zn}_{y} \mathrm{SiO} \mathrm{O}_{5}: 1$ at $\% \mathrm{Eu}^{2+}$ yellow fluorescence phosphor where Zn ranges from 0 to 0.5 moles. 


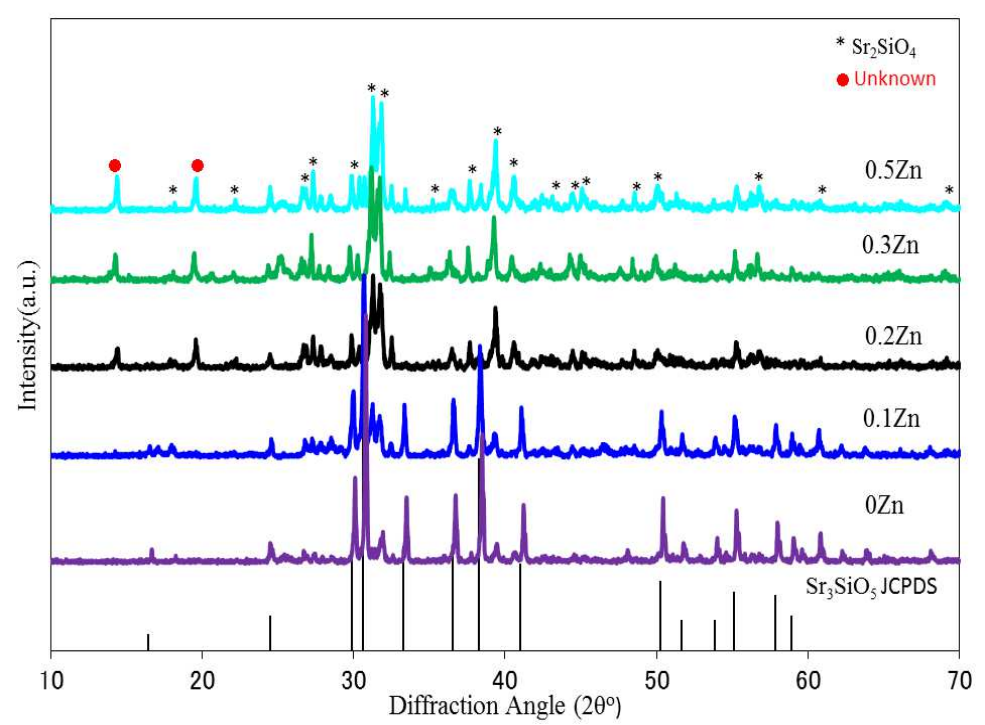

Figure 4. XRD profiles of $\mathrm{Sr}_{2.99-y} \mathrm{Zn}_{y} \mathrm{SiO}_{5}: 1$ at\% $\mathrm{Eu}^{2+}$ yellow fluorescence phosphor as a function of $\mathrm{Zn}$ moles substitution.

By careful investigation on the excitation spectrum of the $\mathrm{Sr}_{2.89} \mathrm{Zn}_{0.1} \mathrm{SiO}_{5}: 1 \mathrm{at} \% \mathrm{Eu}^{2+}$ yellow fluorescence phosphor and phosphorescence spectrum of the extremely long persistent blue white phosphor, it is speculated that the afterglow emission of the blue white phosphor could be used to excite the yellow fluorescence phosphor. For the possibility of efficient energy transfer, the PL quantum yields at various excitation wavelengths of the $\mathrm{Sr}_{2.9-\mathrm{x}} \mathrm{Zn}_{0.1} \mathrm{SiO}_{5}: \mathrm{x}$ at $\% \mathrm{Eu}^{2+}$ phosphor were recorded and presented in Figure 5. While moving towards the longer wavelength excitation side, the PL quantum yield marginally decreased which is still as high as $70 \%$ indicating efficient energy transfer around the phosphorescence spectrum of the extremely long afterglow phosphor chosen. Figure 5 also correlates the PL QY with the Eu concentration at various excitation wavelengths. The PL QY is very high (above $95 \%$ at lower doping concentration) which remained almost constant up to 2 at $\%$ Eu. The PL quantum yield gradually decreased with increasing the $\mathrm{Eu}$ concentration above $2 \mathrm{at} \%$. Further, the PL quantum yield is comparatively low at longer wavelength excitation $(490 \mathrm{~nm})$. Figure 6 shows the radiative energy transfer phenomenon from bluish white component to yellow fluorescence component. The fluorescent component did not show any phosphorescence peak, while the bluish white component showed intense phosphorescence peak around $450 \mathrm{~nm}$. When a small amount of yellow component was thoroughly mixed with the bluish component ( $3 \mathrm{wt} \% \mathrm{BW}+1 \mathrm{wt} \% \mathrm{Y})$, the yellow phosphorescence peak was appeared around $580 \mathrm{~nm}$ corresponding to yellow emission. Further, with the increase of yellow component, the yellow phosphorescence gradually increased and blue phosphorescence decreased. Thus, it was concluded that the radiative energy transfer occurs between blue and yellow components.
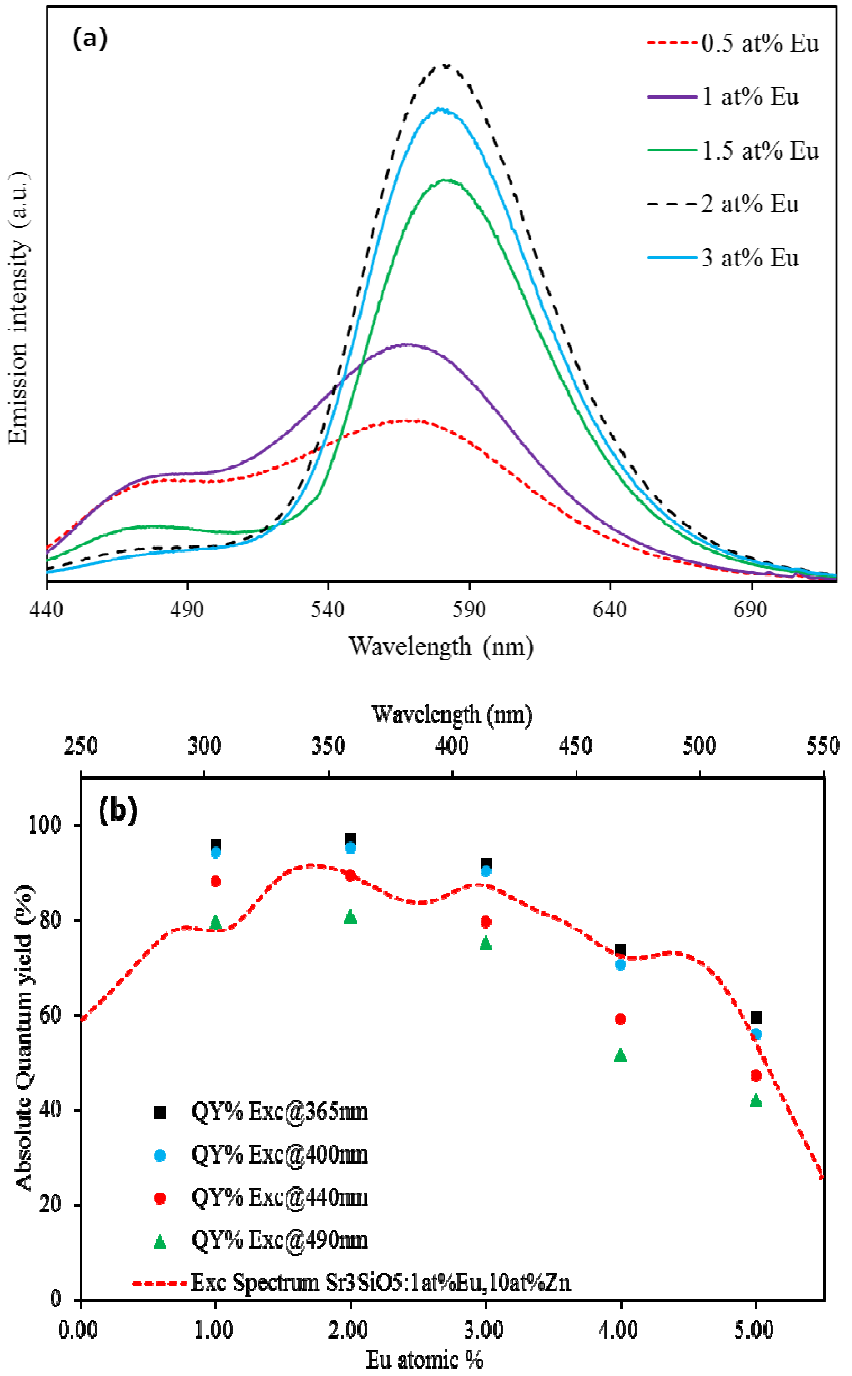

Figure 5. (a) PL emission spectra (ex@365nm black light) and (b) PL excitation spectrum (em@565nm) and excitation wavelengths dependent absolute quantum yield of various moles Eu doped $\mathrm{Sr}_{2.9-x} \mathrm{Zn}_{0.1} \mathrm{SiO}_{5}: \mathrm{x}$ at\% $E u^{2+}$ phosphors. 


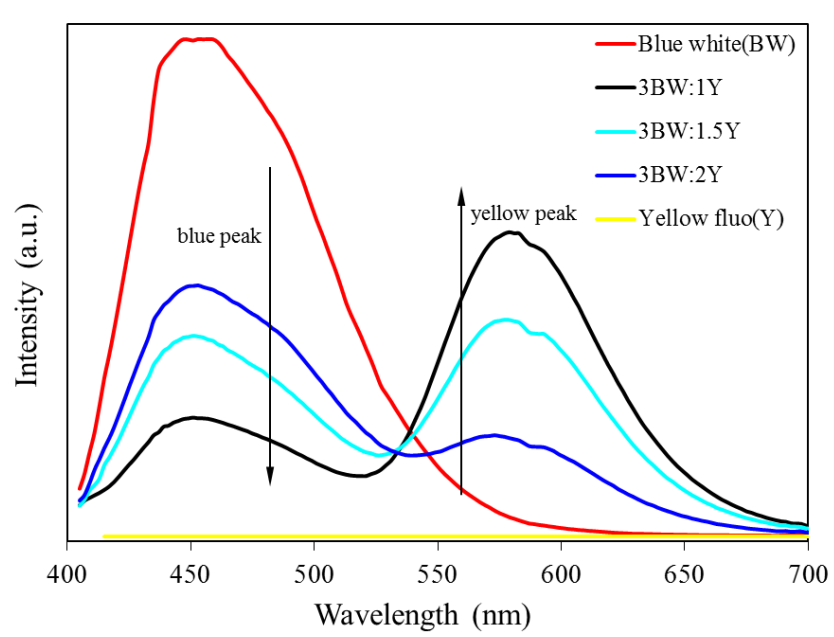

Figure 6. Phosphorescence spectra of various composites of blue white and yellow phosphors showing the radiative energy transfer phenomenon.

Figure 7 shows the white fluorescence and phosphorescence generated by the energy transfer from afterglow of extremely long blue white phosphor to the yellow fluorescence phosphor. The excitation spectrum of the $\mathrm{Sr}_{2.89} \mathrm{Zn}_{0.1} \mathrm{SiO}_{5}: 1$ at $\% \mathrm{Eu}^{2+}$ phosphor was closely overlapped with the phosphorescence spectrum of the blue-white phosphor, thus continuously exciting the yellow fluorescence phosphor. Though the later process is a fluorescence, it is virtually seems to be phosphorescence. Then, the yellow emission color from the $\mathrm{Sr}_{2.89} \mathrm{Zn}_{0.1} \mathrm{SiO}_{5}: 1$ at $\% \mathrm{Eu}^{2+}$ phosphor get mixed with the remaining blue white emission color of afterglow phosphor exhibiting white color of the composite phosphor. The corresponding CIE color chromaticity diagram is presented in Figure 8. The phosphorescence color of the composite phosphor was dependent on the extent of overlap between the excitation wavelength of yellow fluorescence component and phosphorescence wavelength of the afterglow components. Smaller the overlap extent, lower is the energy transfer and weaker will be the white color intensity and stronger the remaining blue white color. The inter-mixing of the colors generates cool white afterglow of the composite phosphor. Maximum the overlap extent, stronger will be the yellow fluorescence leaving weak blue white color and hence the composite phosphor exhibits intense warm white phosphorescence color. Figure 9 shows the phosphorescence curves of the white composite phosphor recorded after excited by black light $(365 \mathrm{~nm})$ for 20 minutes. It is well seen that the clear white phosphorescence was generated by the white composite phosphor at various time intervals. Figure 9 also shows the phosphorescence curve of the blue white phosphor containing broad peak around $450 \mathrm{~nm}$. But the white phosphorescence curves contain peaks at $450 \mathrm{~nm}$ (corresponding to blue white phosphorescence) and broad peak around $580 \mathrm{~nm}$ (corresponding to yellow fluorescence). This proves that the blue phosphorescence is continuously transferred to the yellow fluorescence. As a result white phosphorescence is generated for long time. Another important factor that governs the energy transfer phenomena is particle size/grain size of the components of the composite phosphor. If the grain size is bigger, the interaction extent will be smaller and the energy transfer process will suppress. The grain size of the $\mathrm{Sr}_{2.89} \mathrm{Zn}_{0.1} \mathrm{SiO}_{5}: 1$ at $\% \mathrm{Eu}^{2+}$ phosphor is very fine in the range of few tens of $\mathrm{nm}$ to hundreds of $\mathrm{nm}$, however the grain size of the blue white afterglow phosphor was relatively larger in the order of few micrometer as shown in Figure $10(\mathrm{a}, \mathrm{b})$. Figure 10 (c) shows the SEM image of white composite phosphor. It is clearly seen that the tiny particles of yellow component surround the blue white component. The phosphorescence of blue white afterglow phosphor continuously excites the yellow florescence particles surrounding it, as a result white phosphorescence is observed. For the homogenous white afterglow, the particles dimensions are desired to be as smaller as possible such that intermixing is smooth. If the grain size was larger than $10 \mathrm{um}$, the component particle interaction was inefficient and composite phosphor shows inhomogeneity or two distinguished color.

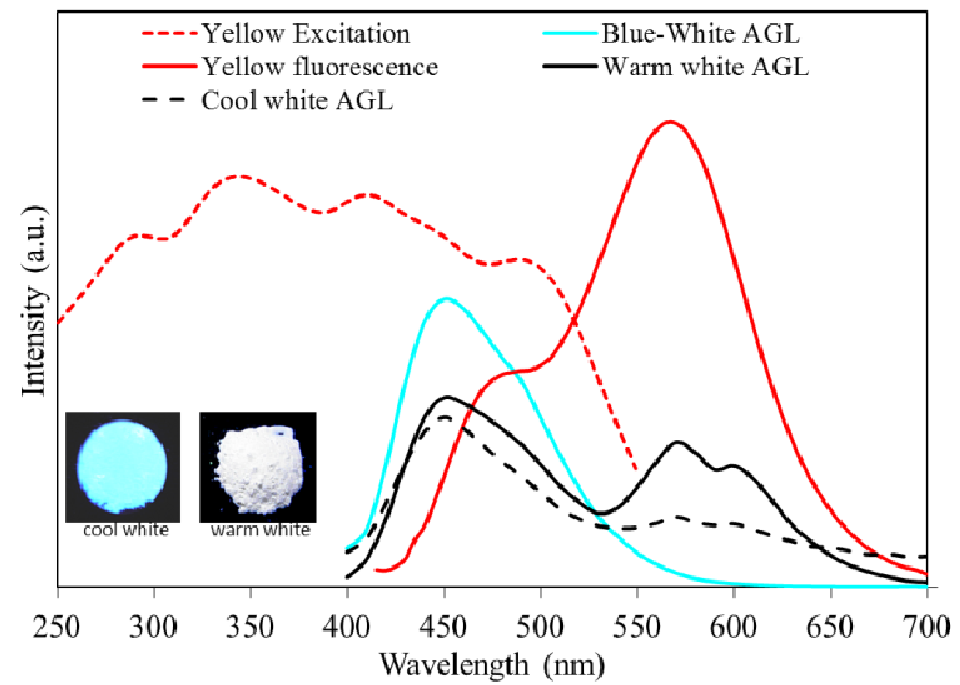

Figure 7. PL excitation (em@580nm), fluorescence (exc@450nm) of yellow Sr ${ }_{2.89} \mathrm{Zn}_{0.1} \mathrm{SiO}_{5}: 1$ at\% Eu ${ }^{2+}$ phosphor and phosphorescence spectra of blue-white and white composite phosphors (inset are the optical photographs of cool-white and warm-white composites). 


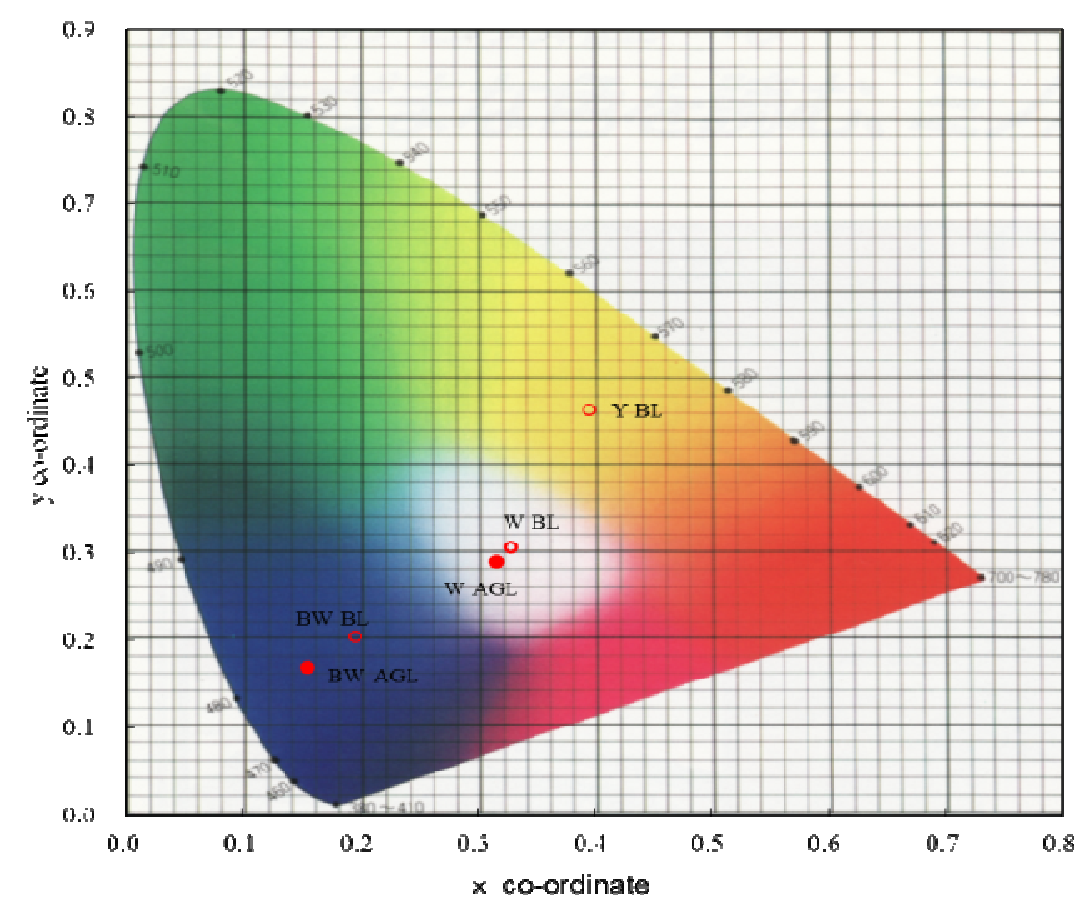

Figure 8. CIE color graphs of bluish white (BW) afterglow phosphor, yellow fluorescent phosphor and white composite phosphors in black light exposure (open circles) and afterglow (solid fills).

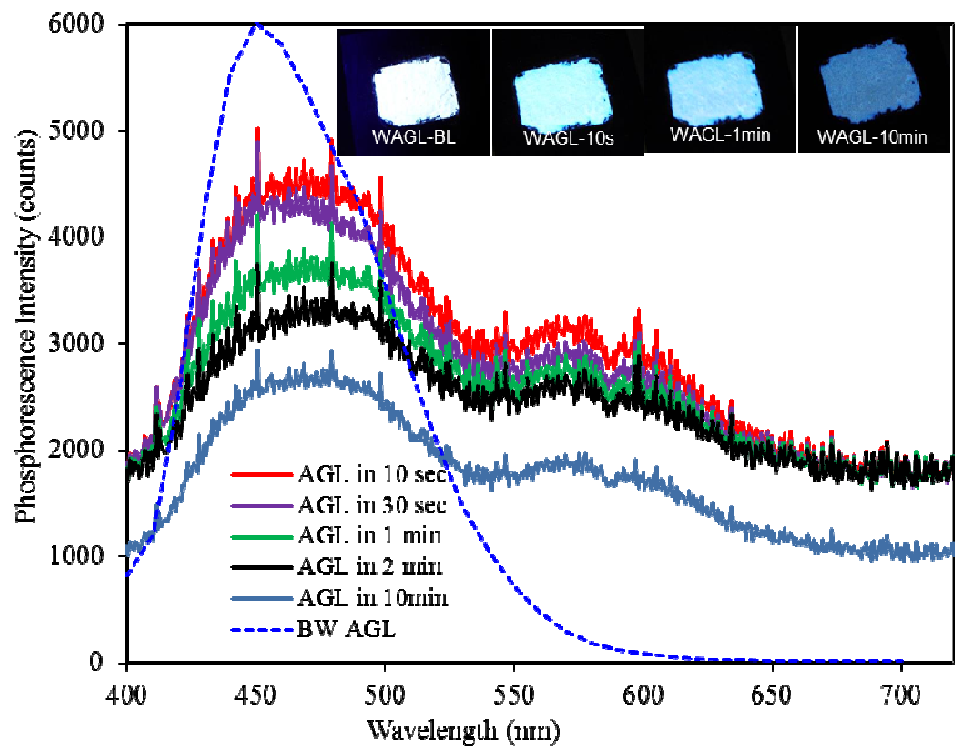

Figure 9. Phosphorescence spectra of white AGL composite phosphors at various time intervals compared to the phosphorescence spectra of BW phosphor. Inset is the optical photographs at various time intervals.
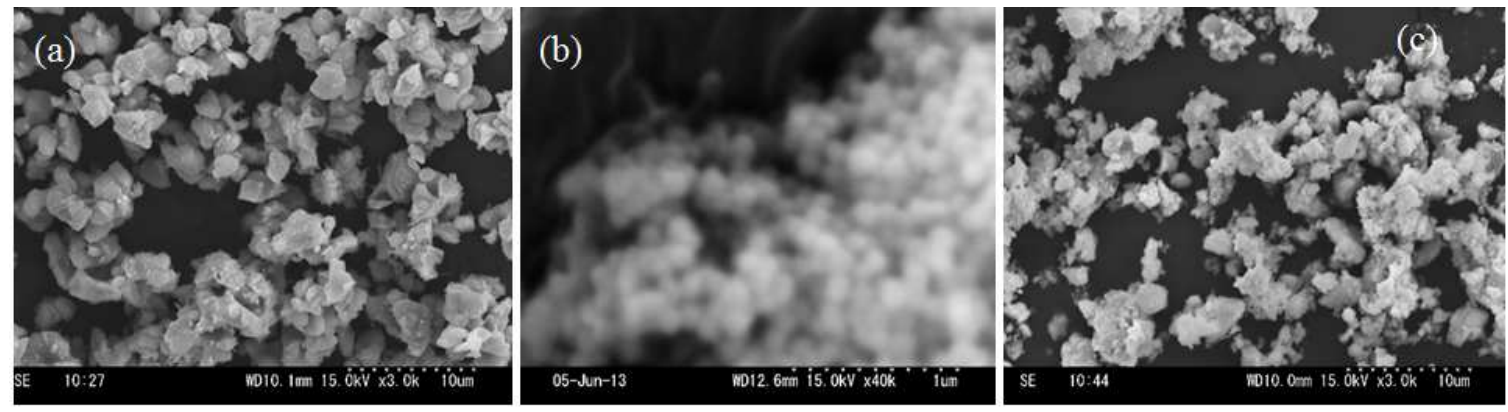

Figure 10. SEM images of bluish white AGL phosphor (a), yellow fluorescence phosphor (b), and white AGL composite phosphor (c). 


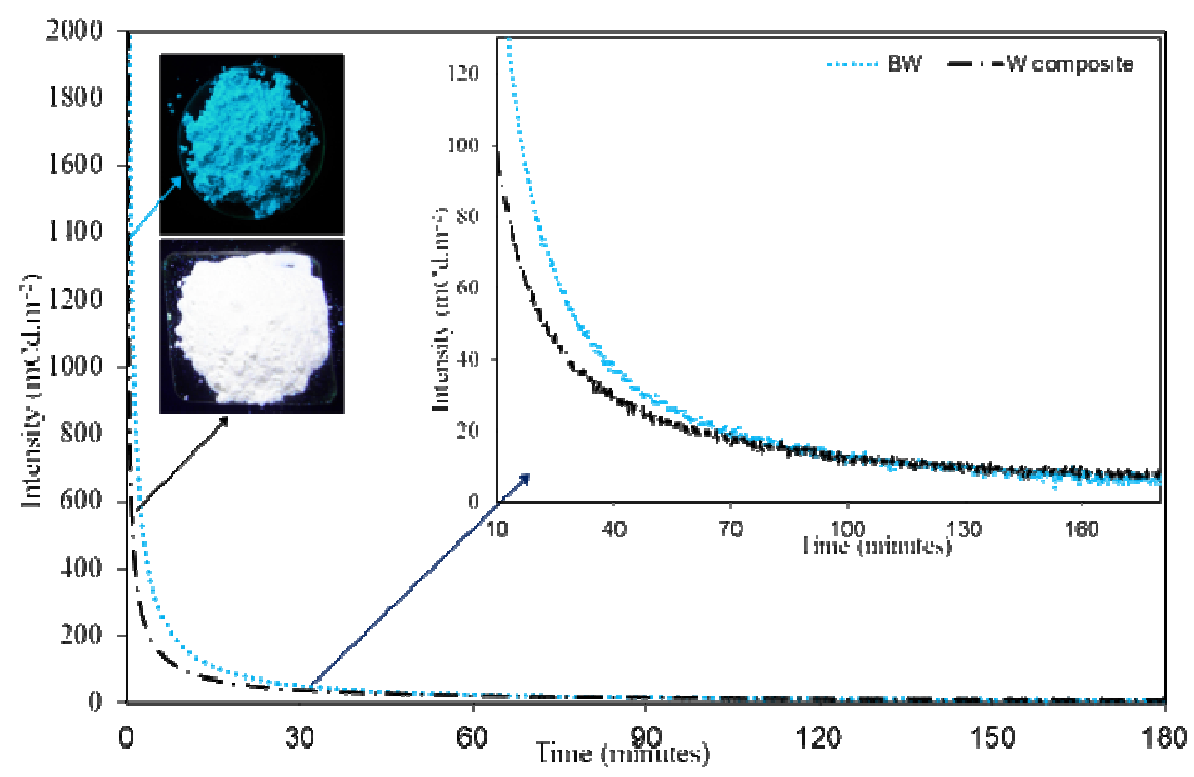

Figure 11. Afterglow decay curves of bluish white phosphor and white composite phosphor (after black light irradiation for 20 minutes). Inset shows the enlarged graph and optical photographs of corresponding phosphors.

Figure 11 shows the afterglow decay phenomena of the extremely long persistent blue white phosphor and the white composite phosphor prepared by blue white AGL phosphor to yellow fluorescence phosphor in the ratio of 3:1. Though the brightness (in mcd. $\mathrm{m}^{-2}$ ) was relatively higher for the blue white phosphor, the brightness of the white composite phosphor was comparable. The lower brightness of the white composite phosphor was due to the energy loss during the energy transfer process since at least $20 \%$ energy was lost due to about $80 \%$ absolute efficiency of the yellow fluorescence phosphor over the blue white phosphorescence spectrum. The afterglow decay trend was very similar to that of the blue white afterglow phosphor. The afterglow emission of the white composite phosphor persists for longer than 6 hours over the value 5 mcd. $\mathrm{m}^{-2}$ while that of blue white persists more than 10 hours.
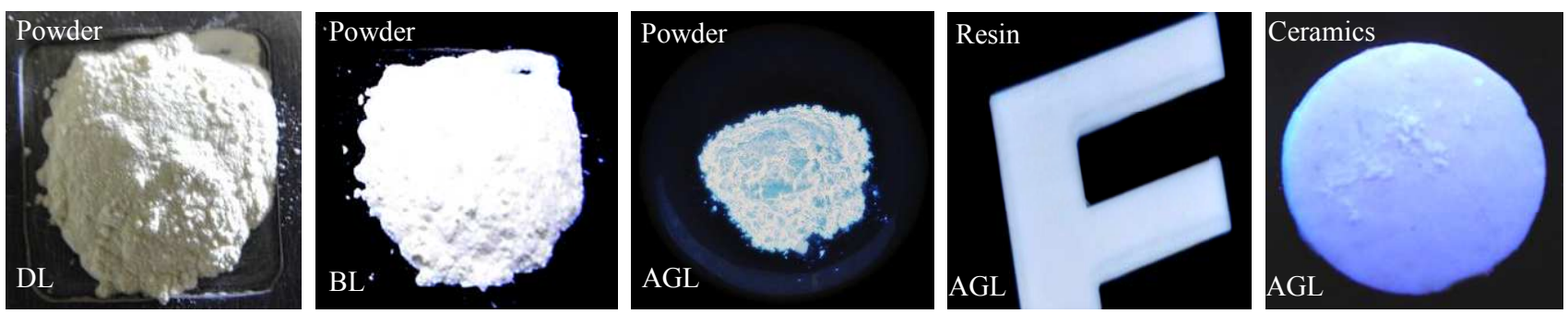

Figure 12. Optical photographs of white composite phosphors in its powder, resin and ceramics forms during day light (DL), black light (BL) and afterglow $(A G L)$.

The white composite phosphor exhibits whitish color during day light, bright white color in black light while slightly cool white color in the dark as shown in the Figure.12. Further, the hard disk of the phosphor can be easily prepared by mixing with the colorless epoxy or silicon resin or by sintering with the low melting glass frits as shown in Figure.12 without altering the emission, afterglow and decay characteristics, elaborating its use in various forms.

\section{Conclusions}

Very bright, cool to warm white persistent composite phosphor was developed by the energy transfer process. The white afterglow composite phosphor comprises composite particles; each of the composite comprises at least two types of phosphor particles having different emission spectrums (colors). Each composite phosphor particles includes an extremely long bluish white afterglow phosphor $\left(\mathrm{CaAl}_{2} \mathrm{O}_{4}: \mathrm{Eu}^{2+}, \mathrm{Nd}^{3+}, \mathrm{Dy}^{3+} / \mathrm{Sr}_{4} \mathrm{Al}_{14} \mathrm{O}_{25}: \mathrm{Eu}^{2+}, \mathrm{Dy}^{3+}, \mathrm{Ag}^{+}\right) \quad$ and high efficient yellow fluorescence phosphor $\left(\mathrm{Sr}_{2.89} \mathrm{Zn}_{0.1} \mathrm{SiO}_{5}: 1\right.$ at $\left.\% \mathrm{Eu}^{2+}\right)$. The highly efficient yellow fluorescent phosphor was modified by doping different concentration of $\mathrm{ZnO}$ such that the excitation spectrum gets overlapped as much with the phosphorescence spectrum of the blue white afterglow phosphor. Then the phosphorescence of the blue white persistent phosphor was continuously transferred to the yellow fluorescence phosphor and hence the composite phosphor exhibits white emission due to mixing of the yellow fluorescence and the remaining blue white phosphorescence. Further, the emission color of the composite phosphor could be well tuned by the proportions of the yellow fluorescence phosphor and blue 
white persistent phosphor. The composite phosphor can be prepared in the form of powders, powder-resin compacts as well as ceramics discs and is suitable in a variety of applications for the manufacture of luminous materials, night vision apparatus and warning signs and symbols.

\section{References}

[1] W.M. Yen, S. Shionoya, H. Yamamoto, Phosphor Handbook, $2^{\text {nd }}$ edition, CRC Press, Newyork, 1998.

[2] M. Sonoda, M. Takano, J. Miyahara, H. Kato, Computed radiography utilizing scanning laser stimulated luminescence, Radiology 148 (1983) 833-838.

[3] R. Chen, S.W.S. Mckeever, Theory of Thermoluminescence and Related Phenomena. World Scientific, Singapore, 1997.

[4] G. Blasse, B.C. Grabmair, Luminescence Materials, Springer, Berlin, 1994.

[5] K. Tomeyosi, Japanese Patent A-51405, 1992.

[6] M. Yamabe, T. Murata, S. Mutagami, H. Ueda, Japanese Patent A-111075, 1989.

[7] T. Masayosi, Japanese Patent A-200388, 1989.

[8] T. Masayosi, Japanese Patent A-200389, 1989.

[9] H. Yamamoto, T. Matsuzawa, Mechanism of long phosphorescence of $\mathrm{SrAl}_{2} \mathrm{O}_{4}: \mathrm{Eu}^{2+}, \mathrm{Dy}^{3+}$ and $\mathrm{CaAl}_{2} \mathrm{O}_{4}: \mathrm{Eu}^{2+}$, $\mathrm{Nd}^{3+}$, J. Lumin.72-74 (1997) 287-289.

[10] F.C. Palilla, A.K. Levine, M.R. Tomkus, J. Electrochem. Soc. 115 (1986) 642.

[11] Abbruscato et. al., J. Electrochem. Soc. 118 (1971) 930.

[12] H.N. Luitel, T. Watari, R. Chand, T. Torikai, M. Yada, Giant Improvement on the Afterglow of $\mathrm{Sr}_{4} \mathrm{Al}_{14} \mathrm{O}_{25}: \mathrm{Eu}^{2+}, \mathrm{Dy}^{3+}$ Phosphor by Systematic Investigation on Various Parameters, J. Materials 2013 (2013) article id 613090.

[13] H.N. Luitel, T. Watari, R. Chand, T. Torikai, M. Yada, Effects of Particle Size and Type of Alumina on theMorphology and Photoluminescence Properties of $\mathrm{Sr}_{4} \mathrm{Al}_{14} \mathrm{O}_{25}: \mathrm{Eu}^{2+}, \mathrm{Dy}^{3+}$ Phosphor, Research Letters in Materials Science, 2009 (2009) article id 475074.
[14] H.N. Luitel, T. Watari, R. Chand, T. Torikai, M. Yada, Preparation and characteristics of Eu and Dy doped $\mathrm{Sr}_{4} \mathrm{Al}_{14} \mathrm{O}_{25}$ Phosphor, Materials Science Forum 569 (2008) 249-252.

[15] Nemoto and Company, http://wwwnemotocojp/en/products/luminova/indexhtml .

[16] Y. Murayama, N. Tekeuchi, Y. Aoki, T. Matsuzawa, US patent No. 5424, 1995.

[17] A. Katelnikovas, T. Bareika, P. Vitta, T. Justel, H. Winkler, A. Kareiva, A. Zukauskas, G. Tamulaitis, $\mathrm{Y}_{3-\mathrm{x}} \mathrm{Mg}_{2} \mathrm{AlSi}_{2} \mathrm{O}_{12}: \mathrm{Ce}^{3+}$ phosphors - prospective for warm-white light emitting diodes, Opt. Mater. 32 (2010) 1261-1265.

[18] K. Li, C. Shen, White LED based on nanoYAG: $\mathrm{Ce}^{3+} / \mathrm{YAG} \mathrm{Ce}^{3+}, \mathrm{Gd}^{3+}$ hybrid phosphors, Optik 123 ( 2012) 621-623.

[19] S. Ye, F. Xiao, Y.X. Pan, Y.Y. Ma, Q.Y. Zhang, Phosphors in phosphor-converted white light-emitting diodes: Recent advances in materials, techniques and properties, Mater. Sci. Eng.:R 71 (2010) 1-34.

[20] C. Shen, Y. Yang, S. Jin, J. Ming, H. Feng, Z. Xu, White lightemitting diodes using blue and yellow-orange-emitting phosphors, Optik 121(2010) 1487-1491.

[21] D. Zhang, B. Li, A multi-layer phosphor package of whitelight-emitting diodes with high efficiency, Optik 121 (2010) 2224-2226

[22] H. Ryu, K.S. Bartwal, J-Operation by Eu luminescence in $\mathrm{CaAl}_{2} \mathrm{O}_{4}: \mathrm{Eu}^{2+}$ alloys by $\mathrm{Zn}$ substitution, Alloys Compd. 461 (2008) 395-398.

[23] X. Sun, J. Zhang, X. Zhang, Y. Luo, X. Wang, A green-yellow emitting $\beta-\mathrm{Sr}_{2} \mathrm{SiO}_{4}: \mathrm{Eu}^{2+}$ phosphor for near ultraviolet chip white-light-emitting diode, J. Rare Earths 26 (2008) 421-424.

[24] J. Taguena-Martinez, R.A. Barrio, L.E. Sansores, A. Les, I. Ortega-Blake, A cluster calculation of group IV impurities in Si and Ge, J. Non-Crystalline Solids 111 (1989) 178-188.

[25] M. Eto, H. Kamimura, Impurity Bands in Group-IV Semiconductors, Comprehensive Semiconductor Science and Technology 1 (2011) 77-112.

[26] G.F.J. Garlick, Luminescent materials, Oxford University Press, UK, 1949. 